\title{
BAICALEIN IMPROVES IN VITRO DEVELOPMENT RATE AND QUALITY OF PREIMPLANTATION BOVINE EMBRYOS WHEN SUPPLEMENTED TO MATURATION MEDIUM
}

\author{
M. Fakruzzaman ${ }^{1}$, S. Yasmine ${ }^{2}$ and N. Ghanem ${ }^{3, *}$ \\ 1- Department of Genetics and Animal Breeding, Faculty of Animal Science and Veterinary Medicine, \\ Patuakhali Science and Technology University, Out Campus, Khanpura, Babuganj, Barishal-8210, \\ Bangladesh, 2- Department of Pharmacy, Faculty of Life Science, University of Development Alternative, \\ Dhanmondi, Dhaka-1209, Bangladesh,3-Department of Animal Production, Faculty of Agriculture, Cairo \\ University, Giza, Egypt, "Correspnding author E-mail: (nassergo@agr.cu.edu.eg)
}

Received: $21 / 4 / 2020$

Accepted: $17 / 6 / 2020$

\section{SUMMARY}

Baicalein (5,6,7-trihydroxyflavone) is one of the flavonoid, that is traditionally used in Chinese herbal medicine. It has an antioxidant properties and acts as free radical scavengers. However, the effect of baicalein on bovine oocyte maturation and subsequent embryo development is unknown. For this, good quality bovine oocytes recovered from abattoir ovaries were cultured in IVM medium supplemented with various concentrations of baicalein $(0,0.1,1.0$ and $10 \mu \mathrm{M})$ followed by in vitro fertilization and embryo development. The cleavage and blastocyst development rates were recorded at days three and eight after fertilization, respectively. In addition, total cell number and total dead cells (apoptotic) were counted using TUNEL-Hoechst assay. The results indicate that the proportion of blastocysts derived from oocytes treated with baicalein of 1 $\mu M(38.3 \%)$ was greater $(P<0.05)$ than those of control group $(28.7 \%)$. In addition, the percentage of Day eight blastocysts was not significantly different namong the $0.1 \mu M(31.5 \%), 1 \mu M(38.3 \%)$ and $10 \mu M(32.5 \%)$ embryo groups. The percentage of hatched blastocyst on day eight were significantly higher in the group supplemented with $1 \mu M(40.5 \%)$ baicalein than those in the control and $0.1 \mu M(33.3 \%$ and 32.4, respectively). Total cell number per blastocyst was increased $(P<0.05)$ in embryos treated with baicalein at the rate of $1 \mu M$ (150.3 \pm 5.0$)$ compared with the control group $(0 \mu M)$ and $10 \mu M(122.9 \pm 8.9$ and $128.1 \pm 6.2$, respectively). However, there were no significant differences between $1 \mu M(150.3 \pm 5.0)$ and $0.1 \mu M(139.4 \pm 5.7)$. Moreover, the number of apoptotic cells was lower $(P<0.05)$ in blastocysts derived from oocytes treated with baicalein of $1 \mu M(3.6 \pm 0.6)$ than in control (6.4 \pm 1.2$)$ and $10 \mu M$ embryos (7.1 \pm 1.7$)$. In conclusion, this study demonstrates that baicalein is a potent antioxidant that improves the maturation environment on the way to promote the developmental competence of bovine oocytes in vitro and increases hatching rate and the total blastocyst cell numbers by suppressing incidence of apoptosis when supplemented at the concentration of $1 \mu M$.

\section{Keywords: Baicalein, bovine embryos, in vitro maturation, development, apoptosis}

\section{INTRODUCTION}

During in vitro production of bovine embryos, occytes maturation, fertilization and zygote culture play crucial roles to achieve the target goal (AbsalónMedina et al., 2014). For in vitro culture of mammalian embryos, it is widly used in in vitro environment consisting of $5 \% \mathrm{CO}_{2}$ and $95 \%$ air $\left(\sim 20 \% \mathrm{O}_{2}\right.$ total) (Kitagawa et al., 2004). Moreover, high concentration of $\mathrm{O}_{2}$ throughout in vitro culture obstructs embryonic development, due to, created additional reactive oxygen species (ROS) from the cytoplasm of developing embryos (Guérin et al., 2001). These ROS are highly reflect with intracellular macromolecules, like proteins, lipids and DNA, and may cause significant dysfunction including inactivation of enzyme, abnormalities in mitochondria or DNA fragmentation (Guérin et al., 2001). Living organisms have the natural protective equivalents/ROS scavengers, which are intracellular antioxidants that counter balance the negative effects of ROS (Wang et al., 2007). Still during the process of in vitro, antioxidants levels are lower than those in vivo; therefore, several antioxidant supplementation of the medium might improve developmental capability (Ali et al., 2003 and Livingston et al., 2004).

The developmental competences of mammalian embryos by in vitro are still lower compared with that of embryos developed in vivo (Pontes et al., 2009). It is also well documented that both oocytes and embryos are vulnerable to oxidative stress and to any kinds of adverse factors when they are cultured in an in vitro culture system (Feng et al., 2014). As a result, various antioxidants such as dihydroxyflavone (Keum et al., 2011), quercetin (Sovernigo et al., 2017), baicalin (Xiaonan et al., 2016 and Qing et al., 2019), resveratrol (Feng et al., 2014 ) and melatonin (Feng et al., 2014 ) have been added to in vitro culture medium to improve the maturation of oocytes and the developmental competence of preimplantation embryos. 
Flavonoids are phenolic compounds and are widely present in plants, fruits and Chinese herbal medicine (Lin et al., 2007). The structures and functions of flavonoids have evoked considerable interest because of their antioxidant properties (Keum et al, 2011). Moreover, the antioxidant activities of flavonoids have been given much attention due to better antioxidant activities than vitamins $\mathrm{C}$ and $\mathrm{E}$ (Lin et al., 2007). Several flavonoids show potent antitumor properties and can induce apoptosis, differentiation and the cell cycle, probably by virtue of their antioxidant functions (Lee et al., 2007). Flavonoids may have the capacity to inhibit the generation of primary oxygen radicals and subsequent oxidation chains, because they are effective chelators of transition metal ions (Afanas'ev et al., 1989). The number of hydroxyl substitutions in a flavonoid is thought to be a critical factor in its ROS-scavenging ability (Areias et al., 2001).

Baicalein (5,6,7-trihydroxyflavone) is one of the flavonoid, and a major component of Scutellaria baicalensis (Kim et al., 2001). It was reported that baicalein had free radical scavenging an antioxidant activities (Shieh et al., 2000). Moreover, baicalein is an antioxidant (Chen et al., 2000), and an antiinflammatory agent (Lin and Shieh, 1996).

The exact role of baicalein in the development of bovine pre-implantation stage embryos has not been elucidated. This is the first study to investigate the effect of baicalein supplementation during in vitro maturation on development of bovine oocytes. The embryos were then cultured without baicalein.

\section{MATERIALS AND METHODS}

\section{Reagents:}

Unless otherwise mentioned, all the chemicals, reagents, media, and media constituents were purchased from Sigma-Aldrich Chemicals, Germany.

\section{Experimental design:}

Briefly, COCs were cultured in $700 \mu \mathrm{L}$ of IVM (In vitro maturation) medium supplemented with various concentrations of baicalein $(0,0.1,1.0$ and 10 $\mu \mathrm{M})$ in an incubator under a moisture-saturated atmosphere of $5 \% \mathrm{CO}_{2}$ in air for $24 \mathrm{~h}$ at $38.5^{\circ} \mathrm{C}$. All embryo groups were evaluated on Day eight (Day $0=$ IVF) to determine the proportion of embryos that had reached the blastocyst stage and hatched. Blastocysts originated from oocytes treated with different concentration of baicalein were used to assess embryo quality. Non-treated blastocysts were used as the control $(0 \mu \mathrm{M})$.

\section{Oocyte collection and in vitro maturation:}

Ovaries were collected from a local slaughterhouse and transported in normal saline solution at $35-37{ }^{\circ} \mathrm{C}$ to the lab. within $2 \mathrm{~h}$. Cumulus oocyte complexes (COCs) were aspirated from 3-8 $\mathrm{mm}$ follicles using an 18 gauge needle fixed to $5 \mathrm{ml}$ syringe. Oocytes enclosed with 3-5 layers of cumulus cells and homogenous granular cytoplasm were considered as a good quality and were utilized for in vitro maturation.

Cumulus-oocyte complexes were cultured in maturation medium, as described by Nasser et al., (2014). In brief, COCs (55-60 oocytes/group) were washed three-times in maturation medium (TCM199) supplemented with $10 \%(\mathrm{v} / \mathrm{v})$ fetal bovine serum (FBS), $1 \mu \mathrm{g} / \mathrm{mL}$ of estradiol-17 $\beta, 10 \mu \mathrm{g} / \mathrm{mL}$ of FSH, $0.6 \mathrm{mM}$ of cystein, and $0.2 \mathrm{mM}$ of sodium pyruvate and transferred into a well of a 4-well dish containing $700 \mu \mathrm{L}$ of IVM medium for 23 to $24 \mathrm{~h}$ at $38.5{ }^{\circ} \mathrm{C}$ in a humidified atmosphere of $5 \% \mathrm{CO}_{2}$ in air.

\section{In vitro fertilization and embryo culture:}

Samples of frozen semen were thawed at $37^{\circ} \mathrm{C}$ for 30 seconds and sperms were washed twice with Sperm Tyrod's Albumin Lactate Pyruvate medium (Sperm-TALP) containing $10 \mu \mathrm{g} / \mathrm{ml}$ heparin, 2.2 $\mathrm{mg} / \mathrm{ml}$ sodium pyruvate and BSA F-V $(6 \mathrm{mg} / \mathrm{ml})+$ $50 \mu \mathrm{g} / \mathrm{ml}$ gentamycin at $500 \mathrm{~g}$ for $10 \mathrm{~min}$. After washing, a sperm pellet was suspended in $0.5 \mathrm{ml}$ of fresh Fert-TALP medium supplemented with six $\mathrm{mg} / \mathrm{ml} \mathrm{BSA} \mathrm{(fatty} \mathrm{acid} \mathrm{free)}+10 \mu \mathrm{g} / \mathrm{ml}$ heparin +3 $\mu \mathrm{PHE}$ and $50 \mu \mathrm{g} / \mathrm{ml}$ gentamycin. Sperm concentration was adjusted to $1 \times 10^{6}$ spermatozoa $/ \mathrm{ml}$. A total of $500 \mu \mathrm{l}$ of motile sperm suspension was placed in 4-well culture plate. In vitro matured oocytes were washed in Fert-TALP media three times and placed into the sperm suspension and kept at $39{ }^{\circ} \mathrm{C}$ in an incubator under a moisture-saturated atmosphere of $5 \% \mathrm{CO}_{2}$ in air for $18-20 \mathrm{~h}$. After coincubation, cumulus cells were removed by pipetting and the presumptive zygotes were washed and transferred to $700 \mu \mathrm{L}$ of CR1-aa medium (Nasser et al., 2014) supplemented with $44 \mu \mathrm{g} / \mathrm{mL}$ Na-pyruvate, $14.6 \mu \mathrm{g} / \mathrm{mL}$ glutamine, $10 \mu \mathrm{l} / \mathrm{mL}$ penicillinstreptomycin, $3 \mathrm{mg} / \mathrm{mL}$ BSA, and $310 \mu \mathrm{g} / \mathrm{mL}$ glutathione (IVC-I) for three days. Medium was then replaced with fresh one. Embryos (eight-cell stage) were cultured until Day eight of embryonic development (Day $0=$ day of IVF) in medium with the same composition as IVC-I, except that BSA was replaced with $10 \%$ (v/v) FBS (IVC-II). Day eight blastocysts were washed three times in TL-HEPES, transferred to fixative $(4 \%[\mathrm{v} / \mathrm{v}]$ paraformaldehyde prepared in one M PBS), and stored at $4{ }^{\circ} \mathrm{C}$ until the total cell number and total cells dead were counted.

\section{Terminal deoxynucleotidyl transferase dUTP nick- end labeling (TUNEL):}

The TUNEL was performed according to the manufacturer's protocol using an In Situ Cell Death Detection Kit (Roche Diagnostics Corp., Indianapolis, IN, USA). Briefly, fixed blastocysts (n =75) were washed twice with $0.3 \% \quad(w / v)$ polyvinylpyrrolidine (PVP) prepared in one M PBS (PVP-PBS) and then incubated in permeabilization buffer $(0.5 \%$ [v/v] Triton X-100 and $0.1 \%$ [w/v] sodium citrate) for $30 \mathrm{~min}$ at room temperature. After permeabilization, embryos were washed twice in PVP-PBS and incubated in the dark with fluorescently-conjugated terminal deoxynucleotide 
transferase dUTP for one $\mathrm{h}$ at $37^{\circ} \mathrm{C}$. TUNEL-stained embryos were washed with PVP-PBS and incubated in PVP-PBS containing $10 \mu \mathrm{g} / \mathrm{mL}$ Hoechst 33342 for $10 \mathrm{~min}$. After being washed twice with PVP-PBS, blastocysts were mounted onto glass slides and their nuclear configuration was analyzed. The number of cells per blastocyst was determined by counting Hoechst-stained cells under an epifluorescence microscope (Olympus IX71, Tokyo, Japan) equipped with a mercury lamp. TUNEL-positive cells fluoresced red, indicating they were apoptotic, whereas the total number of cells was determined by the extent of blue fluorescence.

Statistical analyses

All data were analyzed using the Statistical Package for the Social Sciences (SPSS) software package for Windows (SPSS v.18; SPSS Inc., Chicago, IL, USA). Data of at least five replicates of each treatment were analyzed with ANOVA, using the general linear model procedure. Results were expressed as the percentage (\%), mean \pm SEM (standard error of the mean). Data on blastocysts development rate was analyzed by one-way ANOVA followed by multiple pairwise comparisons (Tukey's Test). Differences with $P<0.05$ were considered as significant.

\section{RESULTS}

\section{Embryo development rate}

Embryo development rates after culturing in IVM medium supplemented with baicalein are shown in Table 1. The percentage of embryo cleavage was not significantly different among all experimental groups (Table 1). The proportion of blastocysts derived from oocytes treated with baicalein of one $\mu \mathrm{M}(38.3 \%)$ was greater $(\mathrm{P}<0.05)$ than those of control $(0 \mu \mathrm{M})$ group $(28.7 \%)$. In addition, the percentage of Day- 8 blastocysts was not significantly different among $0 \mu \mathrm{M}, 0.1 \mu \mathrm{M}$ and $10 \mu \mathrm{M}$ embryo groups.

\section{Embryo hatching rate}

The percentage of hatched blastocyst on day 8 (Table 1) was significantly higher in the group supplemented with one $\mu \mathrm{M}(40.5 \%)$ baicalein than those in the control and $0.1 \mu \mathrm{M}(33.3 \%$ and 32.4, respectively). In addition, there was no significant difference on embryo hatching rate when baicalein was supplemented at the level of one $\mu \mathrm{M}(40.5 \%)$ and $10 \mu \mathrm{M}(36.6 \%)$.

Table 1. Effect of different concentrations of baicalein on the development of bovine embryos in vitro

\begin{tabular}{|l|c|c|c|c|}
\hline $\begin{array}{c}\text { Concentration of } \\
\text { Baicalein }(\boldsymbol{\mu M})\end{array}$ & $\begin{array}{c}\text { Oocytes } \\
(\mathbf{N})\end{array}$ & $\begin{array}{c}\text { Number of embryos that } \\
\text { underwent cleavage rate \% } \\
(\mathbf{n})\end{array}$ & $\begin{array}{c}\text { Number of embryos that } \\
\text { de veloped to the blastocyst } \\
\text { stage \% }(\mathbf{n})\end{array}$ & Hatched/blastocyst \% (n) \\
\hline $0($ Control) & 408 & $81.6 \pm 2.4(333)^{\mathrm{a}}$ & $28.7 \pm 1.8(117)^{\mathrm{b}}$ & $33.3 \pm 0.8(39)^{\mathrm{b}}$ \\
\hline 0.1 & 420 & $83.6 \pm 2.0(351)^{\mathrm{a}}$ & $31.5 \pm 2.9(130)^{\mathrm{ab}}$ & $32.4 \pm 1.1(42)^{\mathrm{b}}$ \\
\hline 1.0 & 413 & $87.4 \pm 2.7(361)^{\mathrm{a}}$ & $38.3 \pm 1.2(158)^{\mathrm{a}}$ & $40.5 \pm 1.0(64)^{\mathrm{a}}$ \\
\hline 10 & 410 & $81.7 \pm 2.9(335)^{\mathrm{a}}$ & $32.5 \pm 3.7(131)^{\mathrm{ab}}$ & $36.6 \pm 0.9(48)^{\mathrm{ab}}$ \\
\hline
\end{tabular}

${ }^{\mathrm{T}} \mathrm{N}$ : total number of cumulus oocytes complexes.

${ }^{a, b}$ Within a column, means without a common superscript differed $(\mathrm{P}<0.05)$.

\section{Assessment of total cell and apoptotic cell numbers in blastocysts}

The total cell number per blastocyst was higher $(\mathrm{P}<0.05)$ in embryos originated from oocytes treated with baicalein at the rate of one $\mu \mathrm{M}(150.3 \pm 5.0)$ compared with the control $(0 \mu \mathrm{M})$ group $(122.9 \pm 8.9)$ and $10 \mu \mathrm{M}(128.1 \pm 6.2)$, but there were no significant differences between one $\mu \mathrm{M}$ and $0.1 \mu \mathrm{M}(139.4 \pm 5.7)$ groups (Table 2 and Figure1). The number of apoptotic cells (Table 2, Fig. 1) was lower $(\mathrm{P}<0.05)$ in $1 \mu \mathrm{M}$-treated blastocysts $(3.6 \pm 0.6)$ than controls $(6.4 \pm 1.2)$ and $10 \mu \mathrm{M}(7.1 \pm 1.7)$. In addition, there were no significant differences in apoptosis rate between one $\mu \mathrm{M}$ and $0.1 \mu \mathrm{M}$ groups.

Table 2. Effect of baicalein on the quality of Day eight blastocysts (mean \pm SEM)

\begin{tabular}{lccc}
\hline $\begin{array}{l}\text { Concentration of } \\
\text { Baicalein }(\boldsymbol{\mu M})\end{array}$ & $\begin{array}{c}\text { Number of blastocysts } \\
\text { examined }\end{array}$ & $\begin{array}{c}\text { Total number of cells per } \\
\text { blastocyst }\end{array}$ & $\begin{array}{c}\text { Number of apoptotic } \\
\text { cells per blastocyst }\end{array}$ \\
\hline $0($ Control $)$ & 18 & $122.9 \pm 8.9^{\mathrm{c}}$ & $6.4 \pm 1.2^{\mathrm{c}}$ \\
0.1 & 19 & $139.4 \pm 5.7^{\mathrm{ab}}$ & $5.3 \pm 1.0^{\mathrm{abc}}$ \\
1.0 & 19 & $150.3 \pm 5.0^{\mathrm{a}}$ & $3.6 \pm 0.6^{\mathrm{a}}$ \\
10 & 19 & $128.1 \pm 6.2^{\mathrm{bc}}$ & $7.1 \pm 1.7^{\mathrm{bc}}$ \\
\hline
\end{tabular}

$\overline{\mathrm{a}, \mathrm{b}, \mathrm{c}}$ Within a column, means without a common superscript differed $(\mathrm{P}<0.05)$. 


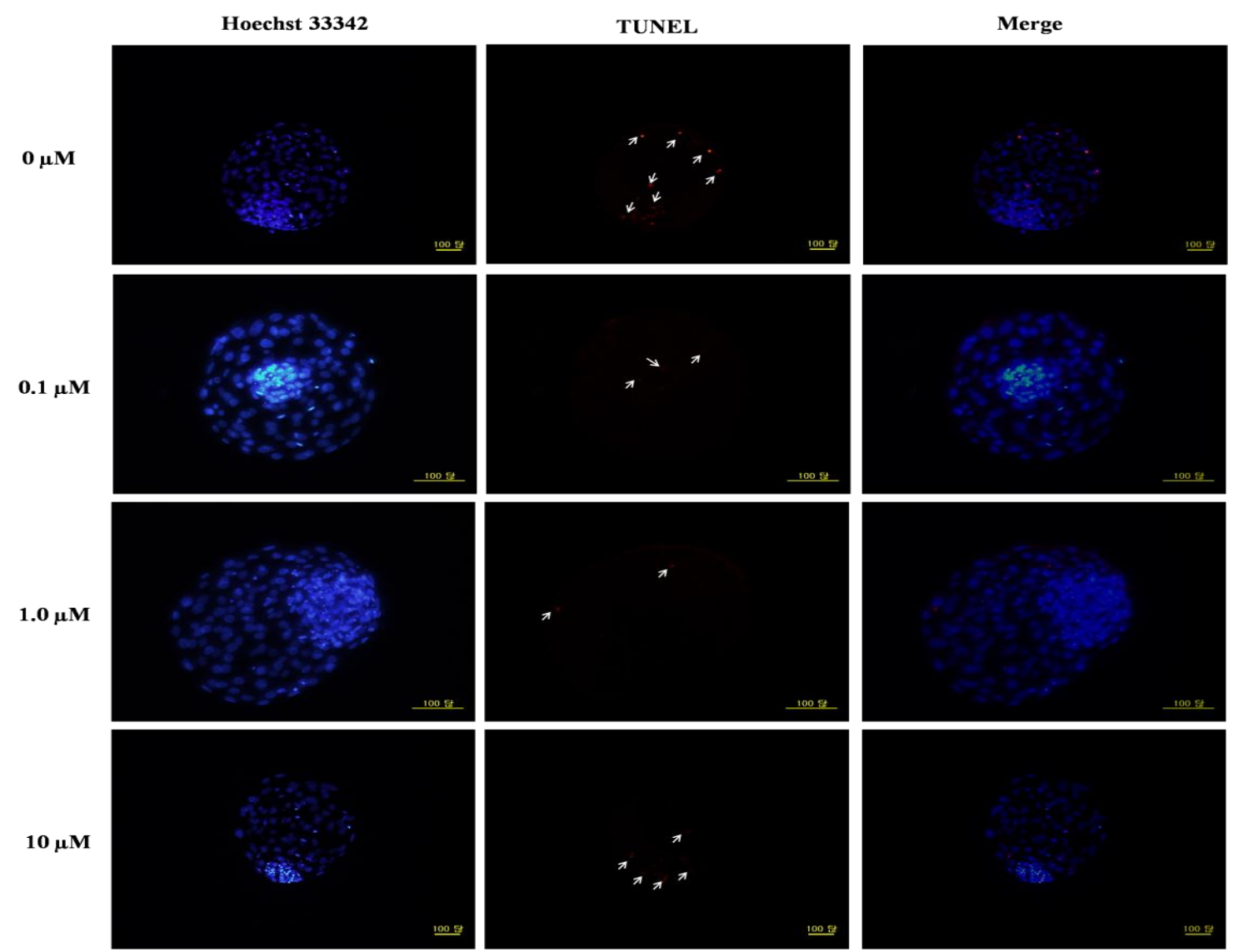

Figure 1. Representative images of bovine embryos stained with Hoechst 33342. Apopt otic cells were identified by terminal deoxynucleotidyl transferase dUTP nick-end labeling (TUNEL). Corresponding images were merged. Scale bar $=100 \mu \mathrm{m}$.

\section{DISCUSSION}

The results of the present study demonstrate that antioxidant flavonoid baicalein has positive effects on in vitro embryo development and increase the total cell numbers while significantly decrease the number of apoptotic cells in the blastocysts. The arrest of embryonic development during in vitro condition is caused by high abundance of ROS resulting from the higher ambient oxygen concentration and relatively lower free radicals scavengers than in vivo condition (Goto et al., 1993). Addition of several antioxidants, those acts as free radical scavengers, to the culture media under normal oxygen conditions may enhance embryo development rate as well as quality (Rocha-Frigoni et al., 2015). This study has demonstrated that baicalein supplementation during oocytes maturation increased blastocyst developmental rates, and promoted proliferation of bovine blastocysts cultured in vitro. Consequently, the percentage of bovine embryos that developed to the blastocyst stage increased compared to that reported for the control group. Several studies have investigated the several compounds of flavonoid groups except baicalein effects on embryonic development rate in bovine (Keum et al., 2011), mouse (Xiaonan et al., 2016), and pig (Qing et al., 2019).

Additionally, reports showed that baicalein has beneficial effects to inhibit of hydrogen peroxide- induced apoptosis in different cells (Shieh et al., 2000). None investigated the influence of supplementing of baicalein to the maturation medium on embryo development and quality. There was no significant difference in the percentage of embryos that underwent cleavage among the groups. However, the percentage of embryos that developed to the blastocyst stage was higher in the one $\mu \mathrm{M}$ treated than in the control $(0 \mu \mathrm{M})$ group. Furthermore, blastocysts developed in the presence of one $\mu \mathrm{M}$ baicalein had higher hatching rates in the present study. These findings are in agreement with other studies, which showed that supplementation of in vitro maturation medium with flavonoids, and resveratrol increases the percentages of bovine, pig and mouse embryos that develop to the blastocyst stage (Feng et al., 2014; Jung et al., 2016, Xiaonan et al., 2016 and Qing et al., 2019). Based on the results above, the effects of baicalein when added to the maturation medium on bovine oocytes increased the developmental competence of embryos compared to the control group.

The supplementation of baicalein to IVM medium improves cells number per blastocyst by reducing the number of apoptotic cells. The total cell number and the apoptotic index are suggested to be important indicators of embryo quality; previous study demonstrated that embryos with a greater number of cells are more likely to implant and to develop into live offspring (Van Soom et al., 2007). 
Furthermore, apoptosis is an important physiological process for eliminating mutated or damaged cells under stressed condition (Yang and Rajamahendran, 2002). Increased incidence of apoptosis in embryonic cells indicates the poor quality of IVC embryos (Fabian et al., 2005).

The treatment with flavonoid substances 3,4Dihydroxyflavone improved the embryo quality when added to the culture medium (Keum et al, 2011). In vitro embryonic culture under high $\mathrm{O}_{2}$ tension enhances to produce more free radicals that have detrimental effect on embryo development (Xiaonan et al., 2016). The addition of baicalein had a positive effect on bovine embryo development by increasing cell numbers in blastocysts. These results are in accordance with other studies that highlighted an increase in the number of total cells and reduction in apoptotic cells when embryos cultured in presence of flavonoids during different culture medium in bovine (Keum et al, 2011), mouse (Xiaonan et al., 2016), and pig (Jung et al., 2016; Qing et al., 2019).

\section{CONCLUSION}

In conclusion, the results of the present study suggest that supplementation of baicalein in culture medium has positive effects for the improvement of maturation environment that promotes developmental competence of bovine embryos and increases the total cell numbers while significantly reducing the apoptotic cell of embryos. Therefore, baicalein is a potent antioxidant that promotes the in vitro developmental capacity of bovine embryos by antioxidant effects. Although our data partially support this idea, further investigations need to identify the exact pathway(s) of baicalein that involved in pronounced improvement of embryo quality.

\section{REFERENCES}

Absalón-Medina, V.A., W.R. Butler, and R.O. Gilbert, 2014. Preimplantation embryo metabolism and culture systems: experience from domestic animals and clinical implications. J. Assist. Reprod. Genet., 31(4): 393-409.

Afanas'ev, I.B., A.I. Dorozhko, A.V. Brodskii, V.A. Kostyuk, and A.I. Potapovitch, 1989. Chelating and free radical scavenging mechanisms of inhibitory action of rutin and quercetin in lipid peroxidation. Biochem. Pharmacol., 38(11): 1763-1769.

Ali, A.A., J.F. Bilodeau, and M.A. Sirard, 2003. Antioxidant requirements for bovine oocytes varies during in vitro maturation, fertilization and development. Theriogenology, 59(3-4): 939949.

Areias, F.M., A.C. Rego, C.R. Oliveira, and R.M. Seabra, 2001. Antioxidant effect of flavonoids after ascorbate/ $\mathrm{Fe}(2+)$-induced oxidative stress in cultured retinal cells. Biochem. Pharmacol., 62(1): 111-118.
Chen, Z.Y., Y.L. Su, Y.R. Bi, S.Y. Tsang, and Y. Huang, 2000. Effect of baicalein and acetone extract of Scutellaria baicalensis on canola oil oxidation. J. Am. Oil. Chem. Soc., 77: 73-78.

Fabian, D., J. Koppel, P. Maddox-Hyttel, 2005. Apoptotic processes during mammalian preimplantation development. Theriogenology, 64: 221-231.

Feng, W., X.Z. Tian, L. Zhang, C. Gao, C.J. He, Y. Fu, P.Y. Ji, Y. Li, N. Li, and G.S. Liu, 2014. Beneficial effects of melatonin on in vitro bovine embryonic development are mediated by melatonin receptor 1. J. Pineal Res., 56: 333342.

Feng, W., X.Z. Tian, L. Zhang, C.J. He, P.Y. Ji, Y. Li, D.X. Tan, and G.S. Liu, 2014. Beneficial effect of resveratrol on bovine oocyte maturation and subsequent embryonic development after in vitro fertilization. Fertil. Steril., 101(2): 577-586.

Goto, Y., Y. Noda, T. Mori, and M. Nakano, 1993. Increased generation of reactive oxygen species in embryos cultured in vitro. Free Radic. Biol. Med., 15(1): 69-75.

Guérin, P., S. El Mouatassim, and Y. Ménézo, 2001. Oxidative stress and protection against reactive oxygen species in the pre-implantation embryo and its surroundings. Hum. Reprod. Update, 7(2): 175-189.

Jung, T.K., J.H. Moon, J.Y. Choi, S.J. Park, S.J. Kim, I.M. Saadeldin, and B.C. Lee, 2016. Effect of antioxidant flavonoids (quercetin and taxifolin) on in vitro maturation of porcine oocytes. Asian Australas. J. Anim. Sci., 29(3): 352-358.

Keum, S.L., E.Y. Kim, K. Jeon, S.G. Cho, Y.J. Han, B.C. Yang, S.S. Lee, M.S. Ko, K.J. Riu, H.T. Lee, and S.P. Park, 2011. 3,4Dihydroxyflavone acts as an antioxidant and antiapoptotic agent to support bovine embryo development in vitro. J. Reprod. Dev., 57(1): 127-134.

Kim, Y.O., K. Leem, J. Park, P. Lee, D.K. Ahn, B.C. Lee, H.K. Park, K. Suk, S.Y. Kim, and H. Kim, 2001. Cytoprotective effect of Scutellaria baicalensis in CA1 hippocampal neurons of rats after global cerebral ischemia. J. Ethnopharmacol., 77: 183-188.

Kitagawa, Y., K. Suzuki, A. Yoneda, and T. Watanabe, 2004. Effects of oxygen concentration and antioxidants on the in vitro developmental ability, production of reactive oxygen species (ROS), and DNA fragmentation in porcine embryos. Theriogenology, 62(7): 1186-1197.

Lee, E.R., J.H. Kim, Y.J. Kang, and S.G. Cho, 2007. The anti-apoptotic and anti-oxidant effect of eriodictyol on UV-induced apoptosis in keratinocytes. Biol. Pharm. Bull., 30(1): 32-37.

Lin, C.C., and D.E. Shieh, 1996. The antiinflammatory activity of Scutellaria rivularis extracts and its active components, baicalin, baicalein and wogonin. Am. J. Chin. Med., 24(1): 31-36. 
Lin, H.Y., S.C. Shen, C.W. Lin, L.Y. Yang, and Y.C. Chen, 2007. Baicalein inhibition of hydrogen peroxide-induced apoptosis via ROS-dependent heme oxygenase 1 gene expression. Biochim. Biophys. Acta., 1773(7): 1073-1086.

Livingston, T., D. Eberhardt, J.L. Edwards, and J. Godkin, 2004. Retinol improves bovine embryonic development in vitro. Reprod. Biol. Endocrinol., 2: 83.

Nasser, G., A.N. Ha, M. Fakruzzaman, J.I. Bang, S.C. Lee, and I.K. Kong, 2014. Differential expression of selected candidate genes in bovine embryos produced in vitro and cultured with chemicals modulating lipid metabolism. Theriogenology, 82: 238-250.

Pontes, J.H., I. Nonato-Junior, B.V. Sanches, J.C. Ereno-Junior, S. Uvo, T.R. Barreiros, J.A. Oliveira, J.F. Hasler, and M.M. Seneda, 2009. Comparison of embryo yield and pregnancy rate between in vivo and in vitro methods in the same Nelore (Bos indicus) donor cows. Theriogenology, 71(4): 690-697.

Qing, G., M.F. Xuan, Z.B. Luo, J.X. Wang, S.S. Jin, X.J. Yin, and J.D. Kang, 2019. Baicalin improves IVM of pig oocytes and subsequent preimplantation embryo development by inhibiting apoptosis. Reprod. Fertil. Dev., 31(5): 983-992.

Rocha-Frigoni, N.A., B.C. Leão, É. Nogueira, M F. Accorsi, and G.Z. Mingoti, 2015. Effects of gaseous atmosphere and antioxidants on the development and cryotolerance of bovine embryos at different periods of in vitro culture. Zygote, 23(2): 159-168.
Shieh, D.E., L.T. Liu, and C.C. Lin, 2000. Antioxidant and free radical scavenging effects of baicalein, baicalin and wogonin. Anticancer. Res., 20: 2861-2865.

Sovernigo, T.C., P.R. Adona, P.S. Monzani, S. Guemra, F. Barros, F.G. Lopes, and C. Leal, 2017. Effects of supplementation of medium with different antioxidants during in vitro maturation of bovine oocytes on subsequent embryo production. Reprod. Domest. Anim., 52(4): 561-569.

Van Soom, A., L. Vandaele, K. Goossens, A. de Kruif, and L. Peelman, 2007. Gamete origin in relation to early embryo development. Theriogenology, 68 (Suppl. 1): S131-S137.

Wang, Z.G., S.D. Yu , and Z.R. Xu, 2007. Improvement in bovine embryo production in vitro by treatment with green tea polyphenols during in vitro maturation of oocytes. Anim. Reprod. Sci., 100(1-2): 22-31.

Xiaonan, Q.I., L.I. Huatao, C. Xia, W. Xin, J. Zhongling, C. Rongfeng, and T. Wenru, 2016. Baicalin increases developmental competence of mouse embryos in vitro by inhibiting cellular apoptosis and modulating HSP70 and DNMT expression. Journal of Reproduction and Development. 62(6): 561-569.

Yang, M.Y., and R. Rajamahendran, 2002. Expression of $\mathrm{Bcl}-2$ and $\mathrm{Bax}$ proteins in relation to quality of bovine oocytes and embryos produced in vitro. Anim. Reprod. Sci., 70: 159169.

\section{البيسلاين يحسن من تطور وجودة أجنة الابقار اثناء التطور الجنيني عند اضافته لبيئة الانضاج

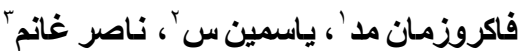

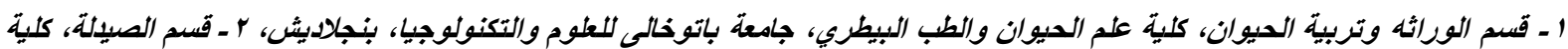

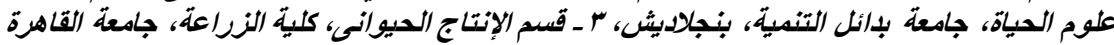

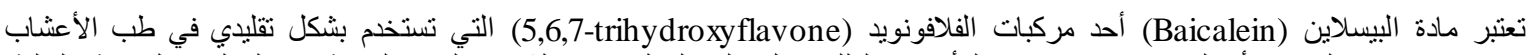

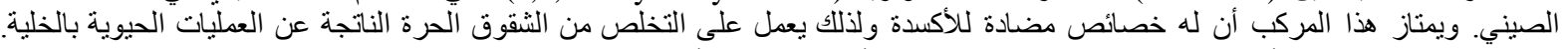

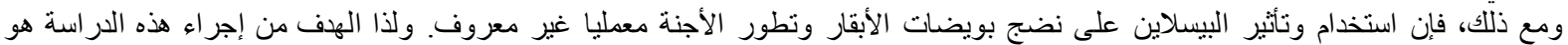

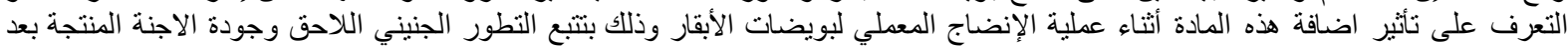

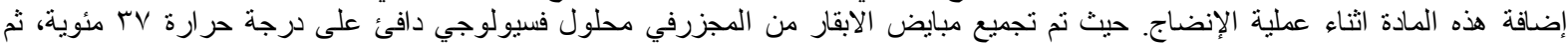

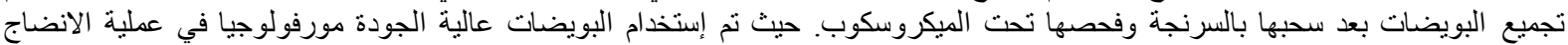

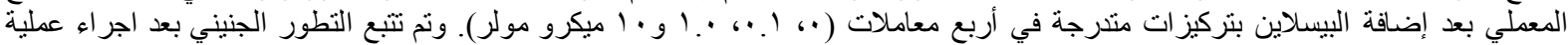

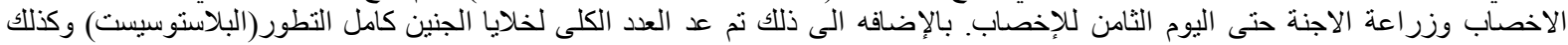

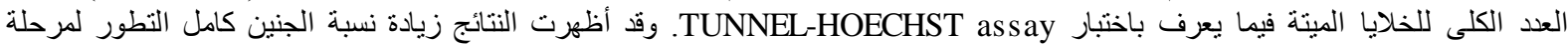

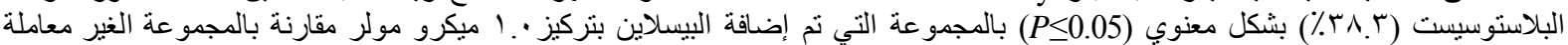

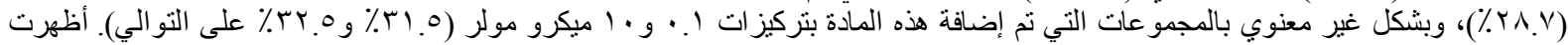

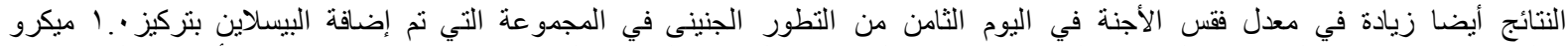

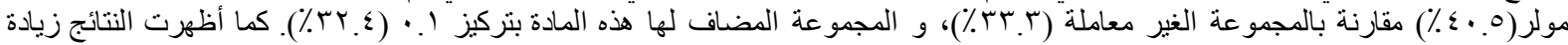

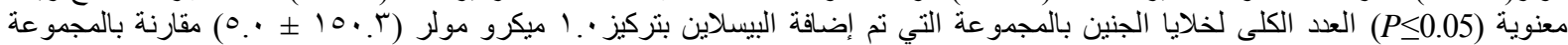

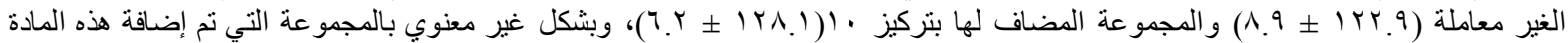

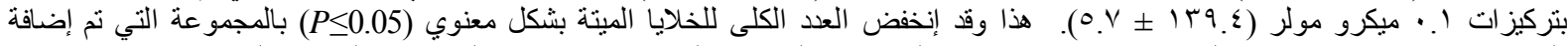

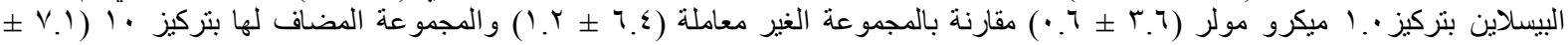

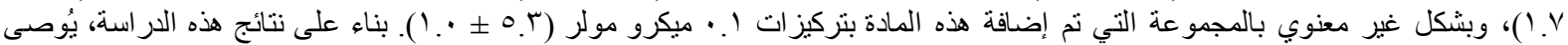

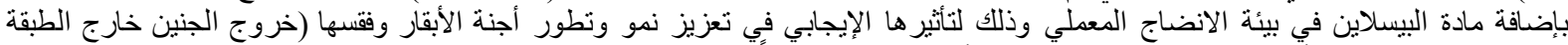

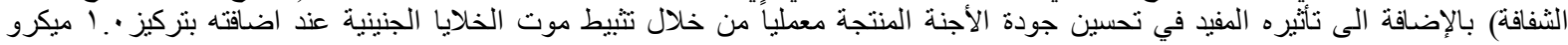

